\title{
FÁCIES SEDIMENTARES E MODELO DE SEDIMENTAÇÃO DA FORMAÇÃO ACAUÃ, PRÉ-CAMBRIANO SUPERIOR NO NORDESTE DA BAHIA
}

\author{
GERSON SOUZA SAES* e GERALDO DA SILVA VILAS BOAS**
}

\begin{abstract}
The upper proterozoic metasedimentary rocks of the Acauã Formation, Estância Group, comprise an assemblage of sedimentary facies indicative of deposition in transitional and shallow marine environments. The basal portion of the formation is composed of supratidal siliceous dolomites. These are overlain, in the intermediate portion by restricted shelf and shelf margin transgressive deposits with frequent mud intercalations indicating periodic dominance of fine terrigenous sedimentation. Typical supratidal black carbonate sediments dominate the upper part of the formation. On this basis, the Acaua Formation is intexpreted as a record of a period of tectonic stability with instalation of a shelf sea along with concomitant widespread marine transgression in the Sergipean Fold Belt domain.
\end{abstract}

INTRODUÇÃo As rochas carbonáticas presentes no Sistema de Dobramentos Sergipano têm recebido especial atenção por parte dos geólogos e deriva de sua importância econômica e complexidade litológica e estrutural a profusão de denominaçбes litoestratigráficas a elas aplicadas: formações Jacoca e Olhos d'Água, Grupo Bambuí, Sequêência Mármore-filftica, formaçōes Cajazeira e Acauã, conforme a localidade geográfica ou o condicionamento geotectônico em que se encontre cada pacote carbonático. Contudo, poucas têm sido as tentativas de caracterização dessas sequüências enquanto materiais que reflitam determinadas condições físico-químicas e biológicas análogas às observadas em regiðes de deposição carbonática moderna.

Este trabalho apresenta o resultado de estudos realizados em rochas carbonáticas do Grupo Estância, em suas exposições na região de Crisópolis e Rio Real no nordeste do Estado da Bahia, constituindo um esforço no sentido de identificar unidades de rochas sedimentares geneticamente significativas, através da descrição sistemática e agrupamento de fácies sedimentares. A interpretação desses dados permitiu a reconsituição dos processos sedimentares atuantes durante a deposição do pacote, bem como a distribuição vertical e geográfica das diferentes fácies e foi utilizada na formulação đe um modelo dinâmico de evolução dos ambientes deposicionais nos quais a acumulação se processou.

CONTEXTO GEOLOGICO REgIONAL A denominação Acauã foi cunhada por Humphrey \& Allard (1969) para se referir a "calcário e dolomito fossilífero, não metamorfisado sub-horizontal" exposto na serra homônima, nas imediações de Euclides da Cunha, Bahia. Esta unidade constitui um horizonte carbonático pertencente à porção inferior e intermediária do Grupo Estância, sequêência metassedimentar do Proterozóico Superior (Humphrey \& Allard op cit., Brito Neves et al. 1977a), amplamente exposta no Estado de Sergipe e nordeste da Bahia, que ocupa uma área de aproximadamente $3.600 \mathrm{~km}^{2}$ e se estende em subsuperfície pelo assoalho das bacias cretáceas de Tucano, Recôncavo e Sergipe-Alagoas. A sul, o Grupo Estância assenta em discordância sobre as rochas cristalinas do Cráton do São Francisco.
As porções mais inferiores do Grupo Estância constituem equivalentes pouco deformados dos Grupos Miaba e Vaza-Barris, com os quais se limitam ao norte através de falhas de empurrão, que consistem em tectonofácies distintas mas cronoestratigraficamente correlatas (Silva Filho $e t$ al. 1977). Estratigraficamente, o grupo está composto por uma sequiência terrígena basal, acumulada em um sistema de leques aluviais, a Formação Juetê. A Formação Acauã inclui depósitos carbonáticos de natureza variada desenvolvidos em planícies de marés e bancos de areias carbonáticas em plataforma marinha rasa. Uma espessa e heterogênea sucessão de sedimentos terrígenos encerra a sedimentação Estância, representada pelas formaçðes Lagarto e Palmares, que registram deposição em plańcie de maré, plataformas lamosas, sistemas de fan deltas, praias e plataformas marinhas denominadas por correntes de maré (Saes \& Vilas Boas 1983, 1984, Saes 1984). Estes ambientes deposicionais gradam ao norte para ambientes de mar profundo, tendo Silva Filho et al. (1978) registrado a ocorrência de turbiditos na Formação Palmares, desmembrando a mesma do Grupo Estância por assentar em discordância sobre as demais formações e constituir uma típica molassa de antefossa. Para norte da região de Lagarto, a Formação Acauã encontra equivàlência nos metassedimentos cálcio-pelíticos das formaçōes $J_{a}$ coca, Capitão e Olhos d'Agua, componentes dos Grupos Miaba e Vaza-Barris, afetadas por intensa tectogênese no Ciclo Brasileiro, com dobramentos holomórficos e metamorfismo na fácies xistos verdes (Brito Neves et al. $1977 \mathrm{~b}$, Silva Filho et al. op cit.).

FACIES SEDIMENTARES DA FORMAÇÃO ACAUÃ A seqüência de carbonatos da Formação Acauã está representada na região de Rio Real e Crisópolis por exposiçōes que atingem espessuras máximas de $45 \mathrm{~m}$. Assenta-se sobre as rochas granito-gnáissicas do Cráton São Francisco em contato tectônico, como a leste de Crisópolis, ou sobre arenitos da Formação Juetê em contato brusco, sendo recoberta por arenitos finos e lamitos da Formação Lagarto em contato abrupto, eventualmente erosivo (Fig. 1).

* Departamento de Geologia, UFMT. Av. Fernando Correa da Costa, s/n., CEP 78000 , Cuiabá, MT, Brasil

** Programa de Pesquisa e Pós-Graduação em Geofísica e Instituto de Geociências da UFBA. Rua Caetano Moura, 123, Federação, CEP 40000, Salvador, BA, Brasil 


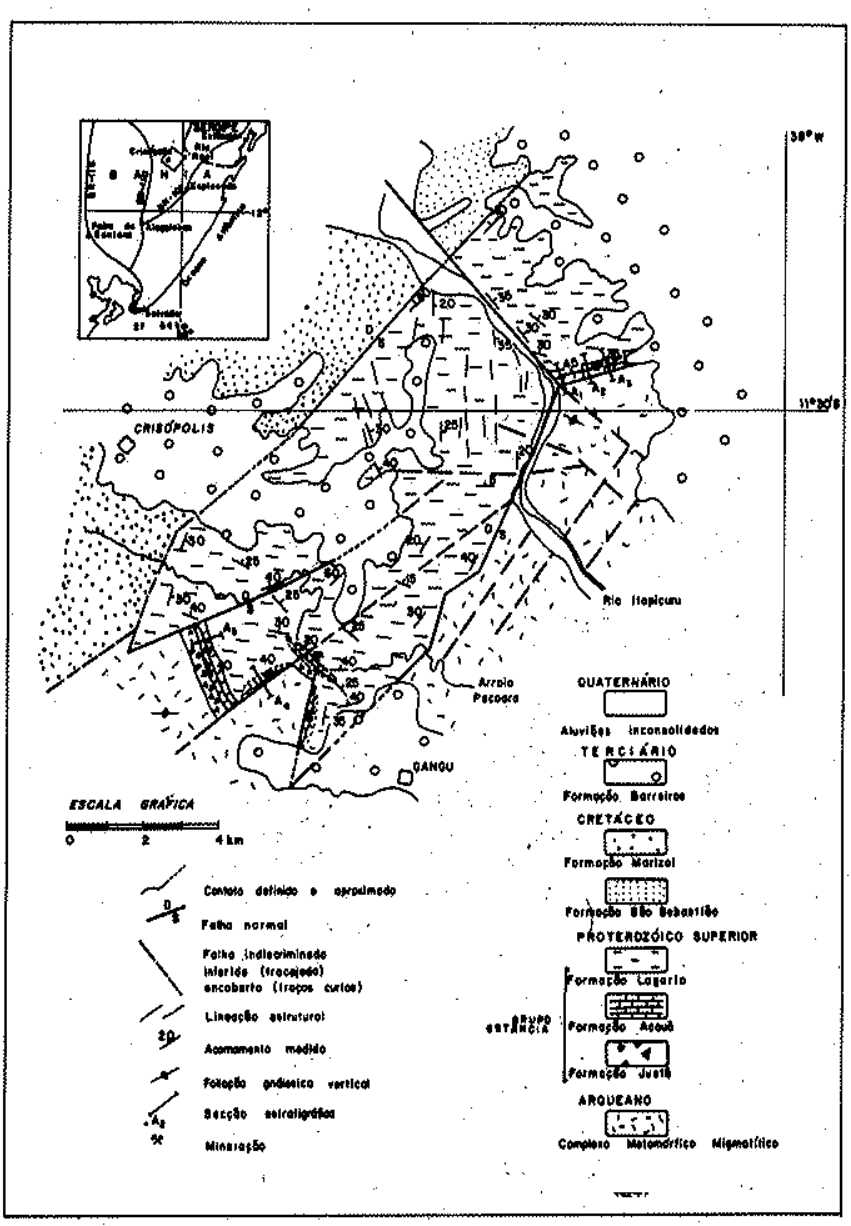

Figura 1 - Mapa geológico simplificado da área

O estudo de diversas exposiçбes da Formação Acauã na região permitiu a subdivisão do pacote de carbonatos em cinco fácies sedimentares: $a$ ) dolomitos silicosos (fácies AS); b) dolomitos cinza maciços e laminados (fácies $\mathrm{AM}$ ); c) calcários dolomíticos e folhelhos calcfferos interestratificados (fácies AT); d) calcários dolomíticos pretos (fácies AN); e e) calcários dolomíticos e calcarenitos oolíticos e bioclásticos interestratificados (fácies $\mathrm{AC}$ ). $\mathrm{O}$ arranjo vertical e lateral destas fácies é mostrado esquematicamente na figura 2. A subdivisão adotada tem o propósito preliminar de examinar isoladamente os tipos sedimentares do ponto de vista dos processos envolvidos em sua deposição, salientando-se contudo alguns aspectos inerentes à inter-relação entre os mesmos: $a$ ) algumas fácies ou subfácies podem recorrer em vários níveis da sucessão, verticalmente distanciados de seu horizonte de maior desenvolvimento (fácies AM, $\mathrm{AT}$ e $\mathrm{AC}$ ); $b$ ) as fácies AN e AC possuem geometria nitidamente lenticular com ocorrências restritas a uma única seção; e c) a transição lateral e vertical entre as diferentes fácies é de natureza gradativa e interdigitada.

Dolomitos Silicosos (fácies AS) Esta fácies domina a porção inferior do pacote de carbonatos e é observada tanto nas exposiçzes da caieira Oitero, ao sul de Crisópolis, como nas pedreiras da Fazenda Areal. Sua espessura gira em tomo de $10 \mathrm{~m}$ e é constiturda por dolomitos cinza

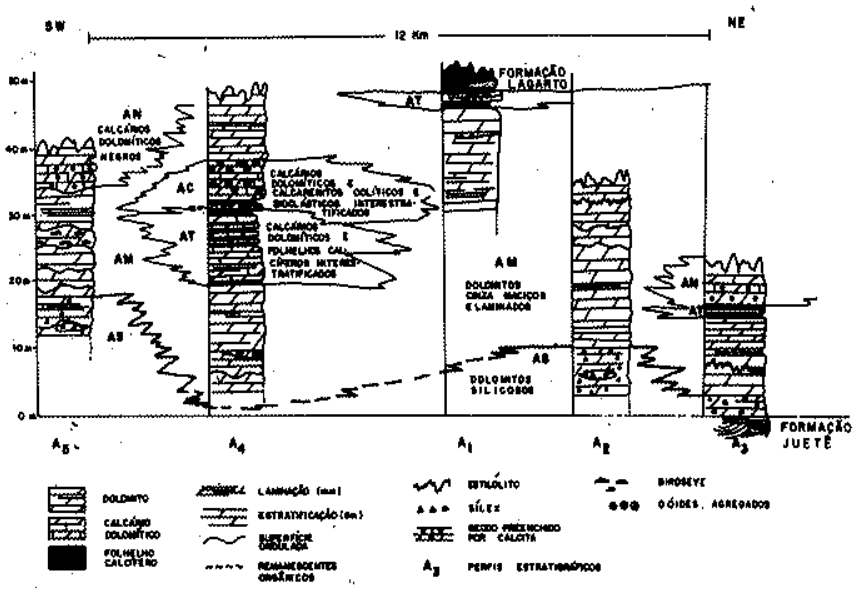

Figura 2 - Arranjo vertical e lateral das fácies sedimentares (AC, AM, AN, AT e AS) da Formação Acauã. Para localizaçäo dos perfis, ver figura 1

microcristalinos, ora em bancos maciços com ate $0,5 \mathrm{~m}$ de espessura, ora em horizontes com laminação plano-paralela milimétrica, fornecida pela alternância de lâminas claras e escuras. A silica que caracteriza a fácies ocorre sob a forma de leitos irregulares de silexito, concordantes com a laminação nos dolomitos, níveis contorcidos, descontínuos $e$ discordantes ou ainda em bolsøes isolados de até $0,7 \mathrm{~m}$ de maior diâmetro, imersos em dolomitos maciços ou laminados.(Foto 1).

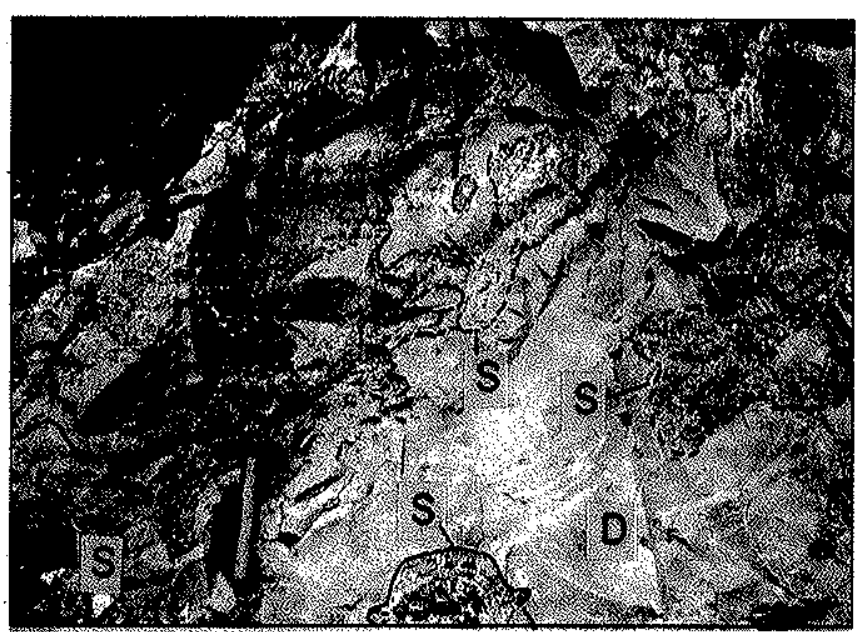

Foto 1 - Aspecto de fácies de dolomitos silicosos (fácies AS). Afloramento exibindo bolsóes e niveis contorcidos e lateralmente interrompidos de silica (S) associados aos dolomitos (D). Pedreira Oiteros, Crisópolis

São comuns nesta fácies as suturas estilolíticas e em suas porçð̄es mais altas é características a presença de cavidades irregulares semi-esféricas de até $1 \mathrm{~cm}$ de diâmetro, preen. chidas parcial ou totalmente por cristais de quartzo ou calcita.

Ao microscópio, os dolomitos se apresentam como ro- 
chas finamente a muito finamente cristalinas e sua laminação resulta da alternância de níveis irregulares e deformados de diferentes graus de cristalinidade $(0,01$ e 0,04 $\mathrm{mm})$. Petrograficamente, podem ser classificados como mudstones (Dunham 1962) ou micritos (Folk 1962). A silica está presente como quartzo microcristalino em lâminas concordantes e alguns níveis mostram também veios preenchidos por carbonatos de granulação em torno de $0,4 \mathrm{~mm}$.

A porosidade observada nesta fácies pode ser descrita como sendo de três tipos principais, adotando-se a classificação de Choquette \& Pray (1970): a) cavidades planares isoladas, acompanhando os planos de laminação (fenestral ou birdseye) com até $8 \mathrm{~mm}$ de dimensão horizontal; $b$ ) cavidades semi-esféricas isoladas (vugs) ou conectadas (channel) independentes da estrutura primária; $\mathrm{e}$ c) fraturas.

Esta fácies tem sua origem ligada a processos de rápido assentamento de lama carbonática em áreas protegidas da ação de correntes persistentes. Embora não tenham sido encontradas estruturas colunares, concêntricas ou esferóides, típicas de estromatólitos, a laminação presente nesses dolomitos pode estar relacionada ao aprisionamento de lamas por películas de algas verde-azuis (cianófitas). A porosidade tipo birdseye tem sido descrita em sedimentos dolomíticos recentes nas Bahamas e na Península de Catar, no Golfo Pérsico. Estas estruturas são preservadas principalmente em sedimentos de supramaré, algumas vezes na intermaré e nunca nos sedimentos de inframaré, e estão geralmente associadas à laminação algal e gretas de contração. A origem desses vazios deve-se ao aprisionamento de ar nas lamas recém-depositadas e formação de bulbos, que são preservados pelo endurecimento de uma crosta superficial durante o período de exposição subaérea (Shinn 1968).

Dolomitos Cinza Maciços e Laminados (Fácies AM) Este é o tipo faciologico predominante em todas as ocorrências da Formação Acauã na região e sua espessura pode atingir até $30 \mathrm{~m}$. Trata-se de dolomitos cinza-claros dispostos em bancos internamente maciços ou laminados com até $0,6 \mathrm{~m}$ de espessura (Foto $2 \mathrm{~A}$ ). $\mathrm{O}$ topo desses estratos pode estar marcado por superfícies de discontinuidade sobre as quais se acumulam finas camadas de alguns centímetros de lama terrígena avermelhada. As estruturas mais comuns são os estilólitos, a laminação plano-paralela com espessura média de $2 \mathrm{~mm}$ e a laminação ondulada (Foto 2B). Para o topo da fácies são freqüentes as intercalações de níveis milimétricos e centimétricos de lamas calćfferas, transicionando para a fácies AT (calcários dolomíticos e folhelhos calcíferos interestratificados).

Em seção delgada constata-se a natureza essencialmente cristalinà dessas rochas com granulação variando de 0,08 a $0,02 \mathrm{~mm}$. É comum a presença de cristais de gipsita disseminados e de veios de até $1,5 \mathrm{~mm}$ de espessura preenchidos por um agregado de gipsita, quartzo e carbonato em cristais de até $0,6 \mathrm{~mm}$. A porosidade, menos desenvolvida que na fácies AS sotoposta, é principalmente dos tipos vugs e fraturas.

As feições presentes nesta fácies são indicativas de que sua deposição teria ocorrido pelo rápido acúmulo de lamas carbonáticas em áreas costeiras extensas, originando uma cobertura lateralmente contínua por toda a região. As superfícies onduladas abundantes nesses dolomitos atestam períodos de emersão dessas áreas, diminuição da lâmina d'água, interrupção da sedimentação carbonática e retraba-
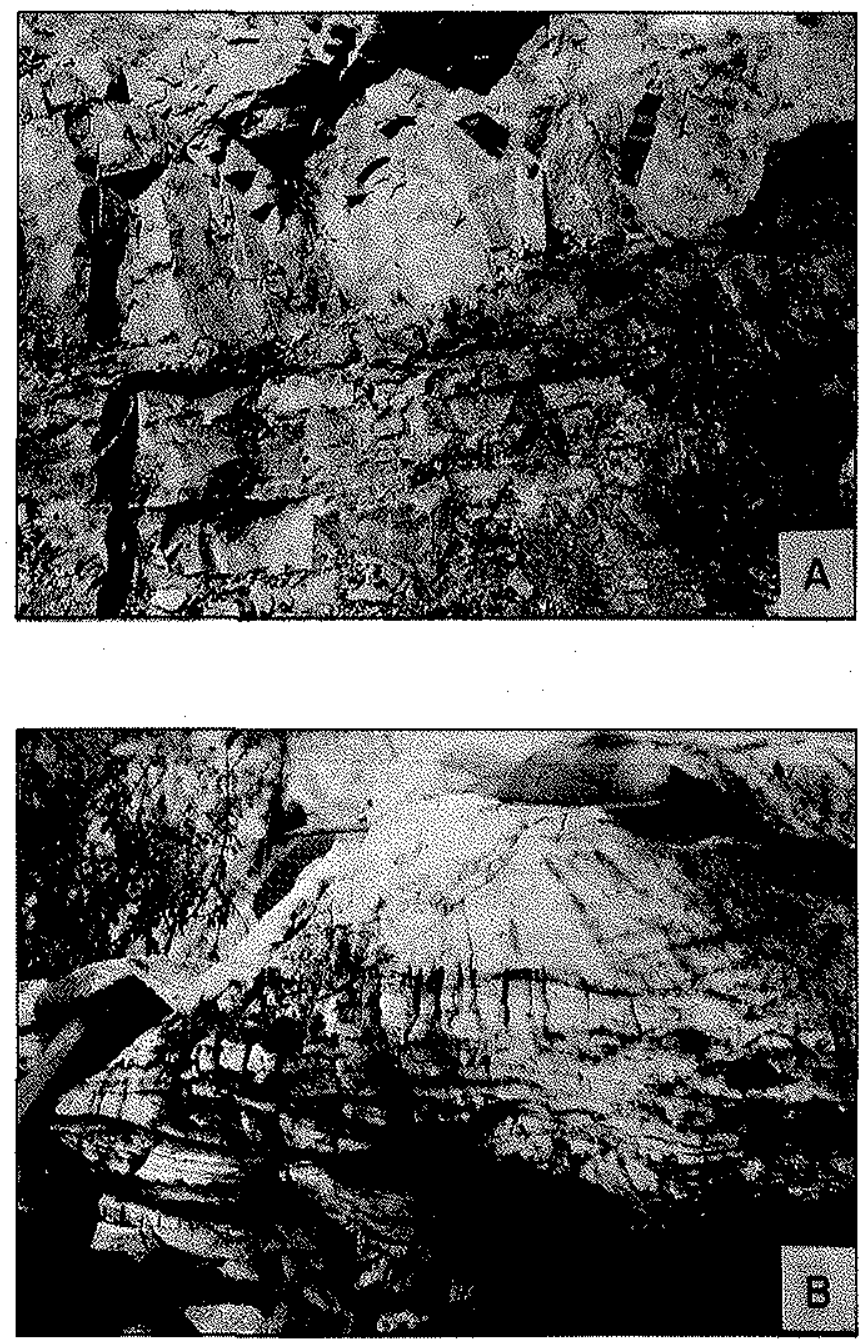

Foto 2 - Fácies de dolomitos cinza maciços e laminados (fácies $A M$ ): A) banco de dolomito laminado na base passando a maciço no topo; B) dolomito com laminaçẫo plano-paralela e ondulada, com algumas suturas estiloliti cas. Afloramento na Fazenda Areal, nordeste da área estudada

Ihamento das superfícies deposicionais por oscilações e fracas correntes. $O$ caráter dolomítico e a presença de gipsita disseminada e preenchendo veios por toda a espessura da fácies sugerem valores de salinidade mais elevados que os de águas marinhas normais para as águas superficiais e intersticiais dessas áreas costeiras. A cristalização de gipsita e dolomita em superfície em uma ampla faixa de planícies costeiras salgadas (sabkhas), associadas a tapetes algais e mangues é um fenômeno típico dos carbonatos recentes da península de Catar no Golfo Pérsico (Bathurst 1976).

Calcários Dolomíticos e Folhelhos Calciferos Interestratificados (Fácies AT) Horizontes de lamas terrígenas de possança variável são comuns ao longo de toda a espessura da pilha de carbonatos da região estudada constituindo, ademais, um nível individualizado na porção média a superior da formação, atingindo espessuras da ordem de $10 \mathrm{~m}$. Na região de Crisópolis, eșta fácies é mais bem desenvolvida nas exposições da pedreira Inorcal e na região da Fazenda 
Areal, ocorrendo entretanto em todas as seções, embora com espessuras bastante reduzidas. Trata-se de calcários dolomíticos cinza-claros, que apresentam efervescência moderada com $\mathrm{HCl}$ diluído (10\%), em camadas de até $15 \mathrm{~cm}$ de espessura, internamente maciças, alternando-se a níveis, de mesma espessura ou mais delgados de folhelhos creme, laminados, calcíferos. Para o topo da unidade a espessura dos níveis argilosos vai diminuindo até constituírem filmes milimétricos separando leitos de poucos centímetros de calcários dolomíticos (Foto 3 ).

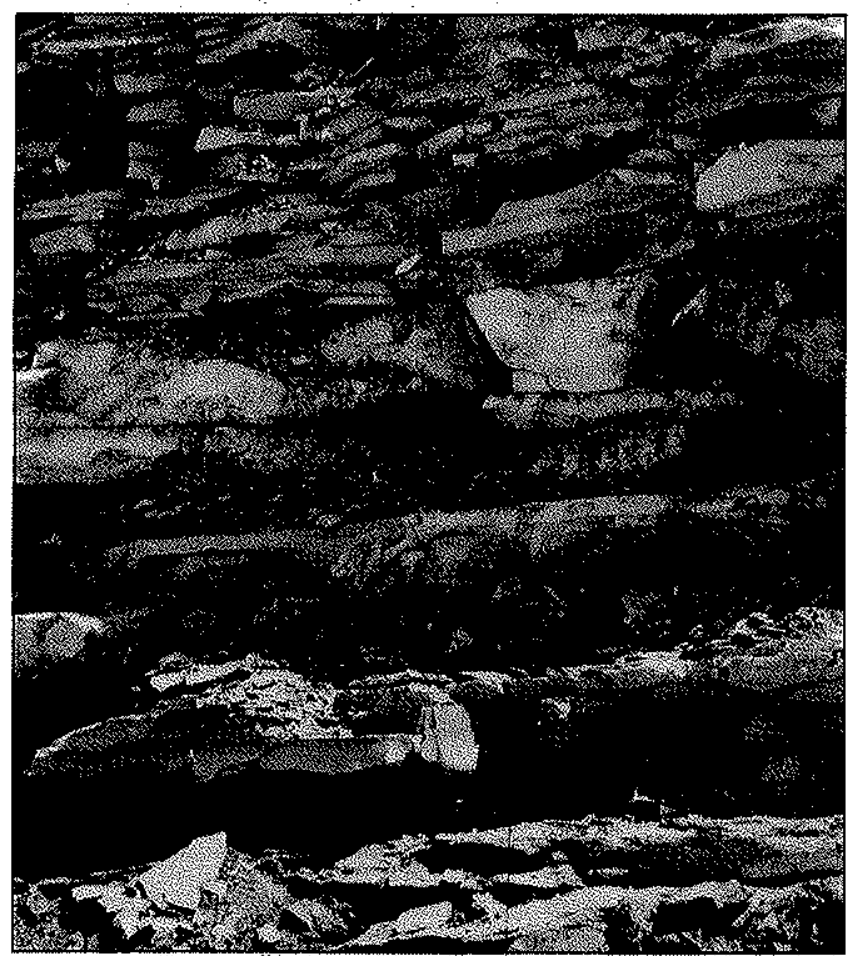

Foto 3 - Fácies de calcários dolomiticos e folhelhos calciferos interestratificados (fácies AT). Alternância de calcário dolomitico e folhelhos creme. Na parte superior, os niveis alternados são menos espessos e produzem o aspecto laminado

A deposição desta fácies ilustra condições de influxo esporádico de material terrígeno fino em suspensão, com turvação das águas, diminuição da profundidade de penetração da luz solar e conseqüentemente inibição da produção de sedimentos carbonáticos. A granulometria fina e a laminação plano-paralela desses folhelhos bem como a interestratificação com lamas carbonáticas texturalmente semelhantes às de fácies $\mathrm{AM}$ indicam a permanência de condições de baixa energia dessas áreas.

Calcários Dolomíticos Pretos (Fácies AN) Observada em uma seção nas caieiras da Fazenda Areal e se estendendo em uma faixa de ocorrências de direção NE até ser encoberta pela Formação Barreiras (Fig. 1) e na caieira Oitero em Crisópolis, esta fácies possui distribuição restrita na região e atinge nestas ocorrências espessura máxima de $10 \mathrm{~m}$. São rochas de cor cinza-escura a preta, em bancos de aproximadamente $0,40 \mathrm{~m}$ de espessura, internamente maciços. Apresentam como características marcantes a presença de cavidades irregulares de até $1 \mathrm{~cm}$ de diâmetro, preenchidas parcial ou totalmente por cristais de calcita de granulação gros- sa, efervescência moderada com $\mathrm{HCl}$ diluído e exalação de forte odor de gás sulfídrico quando percutidas com martelo. Pela intima associação desses calcilutitos pretos com as lamas dolomíticas da fácies AM no topo da formação, sua deposição é tentativamente atribuída à decantação de sedimento carbonático fino em áreas baixas da planície de supramaré sob condições redutoras e anaeróbicas, propícias à preservação de matéria orgânica carbonosa.

Calcários Dolomíticos e Calcarenitos Oolíticos e Bioclásticos Interestratificados (Fácies AC) Esta fácies é encontrada na parte média da seção da pedreira Inorcal sendo tipificada por calcários dolomíticos cinza cristalinos, intercalando diversos níveis de calcarenitos por uma espessura de aproximadamente $10 \mathrm{~m}$. Alguns horizontes centimétricos de folhelhos creme calcíferos se intercalam na seqüência e caracterizam uma passagem gradual entre as fácies AT e AC. Os leitos de calcarenitos atingem espessuras de odem de 30 $\mathrm{cm}$ e exibem nítida lentícularidade na escala de afloramento (Foto 4).

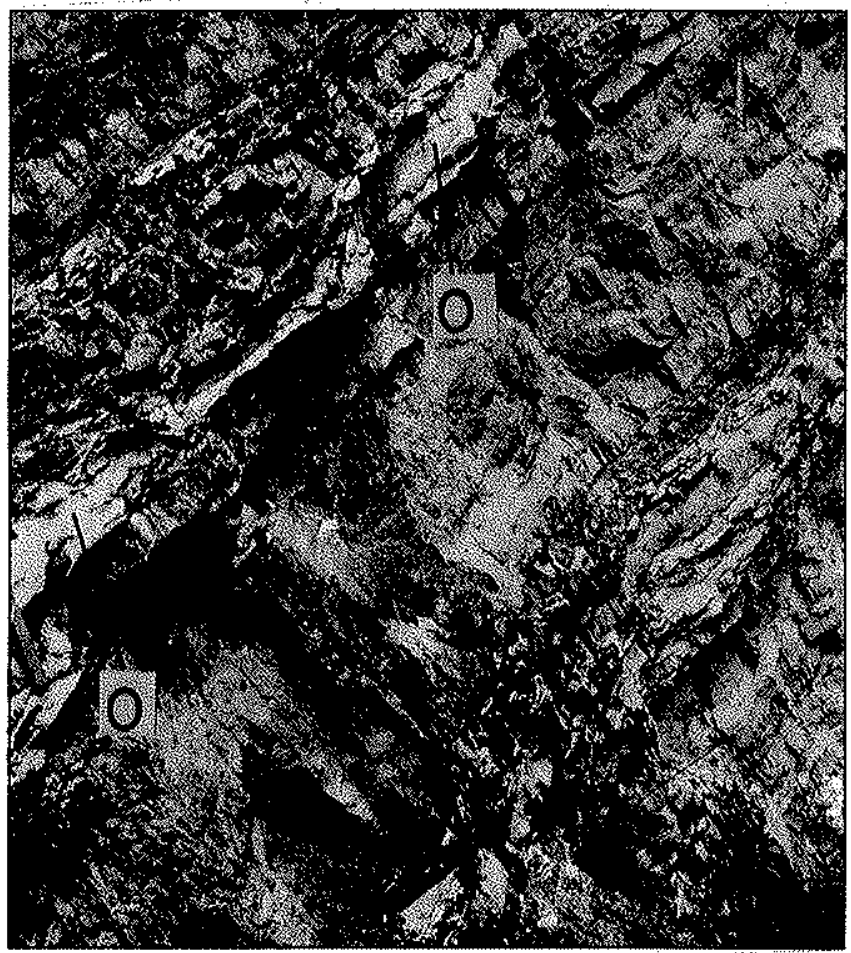

Foto 4 - Fácies de calcarenitos e calcários dolomiticos interestratificados (fácies $A C$ ). Nivel lenticular (O) de calcário oolitico (cor clara) intercalado a calcários dolomiticos e delgadas lâminas argilosas. Pedreira Inorcal, Crisópolis

Os calcarenitos oolíticos podem ser classificados segundo Dunham (1962) e Folk (1962) como grainstones e oosparitos, respectivamente. As formas mais comuns dos oóides são esféricas, ovaladas e elipsoidais, apresentando-se geralmente como oóides superficiais, que mostram uma delgada película de calcita microcristalina envolvendo ora um núcleo de carbonato de granulação grossa ora um núcleo detrítico geralmente quartzoso. Os constituintes subordinados dessas rochas, não atingindo $10 \%$ em volume, são grãos carbonáticos com envol tório de micrita e agregados, compostos por dois ou mais constituintes aloquímicos envol tos por uma crosta esférica de micrita (Foto $5 \mathrm{~A}$ ). 
Os calcarenitos bioclásticos são constituídos por fragmentos organógenos de natureza não identificada, consistindo em filamentos de micrita encurvados com tamanho entre 0,6 e $1 \mathrm{~mm}$ (Foto 5B) e sudordinadamente por obides e fragmentos carbonáticos.
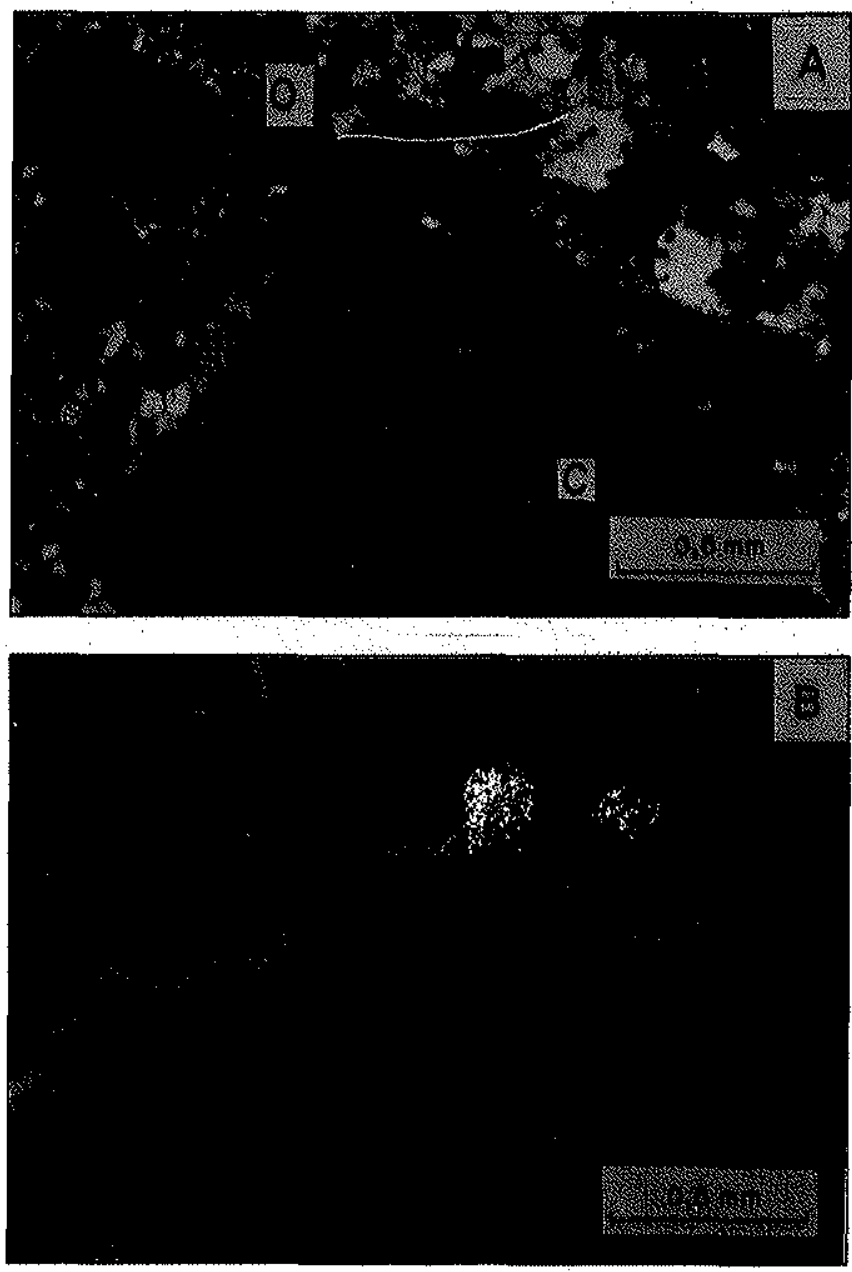

Foto 5 - Fotomicrografia dos calcarenitos da fácies $A C: \mathrm{A})$ grapestones constituidos por agregados de oóides $(O) e$ gräos carbonáticos com envelope de micrita $(C)$; $e$ B) calcarenito bioclástico mostrando filamentos encurvados de micrita, provavelmente remanescentes orgânicos.

A evolução dessas rochas passou por diversas fases, identificadas pelo estudo das texturas apresentadas pelos calcarenitos (Fig. 3).

1) precipitaçâo de uma crosta de calcita espática laminar, em cristais de em média $0,04 \mathrm{~mm}$ (finamente cristalina) orientados perpendicularmente às paredes externas dos grãos;

2) precipitação de um mosaico equigranular muito finamente a finamente cristalino $(0,01$ a $0,05 \mathrm{~mm})$ de cristais desorientados preenchendo os espaços vazios remanes. centes;

3) dissolução seletiva e substituição dos carbonatos primários por dolomita ou snlica, preservando as texturas das fases de cimentação anteriores.

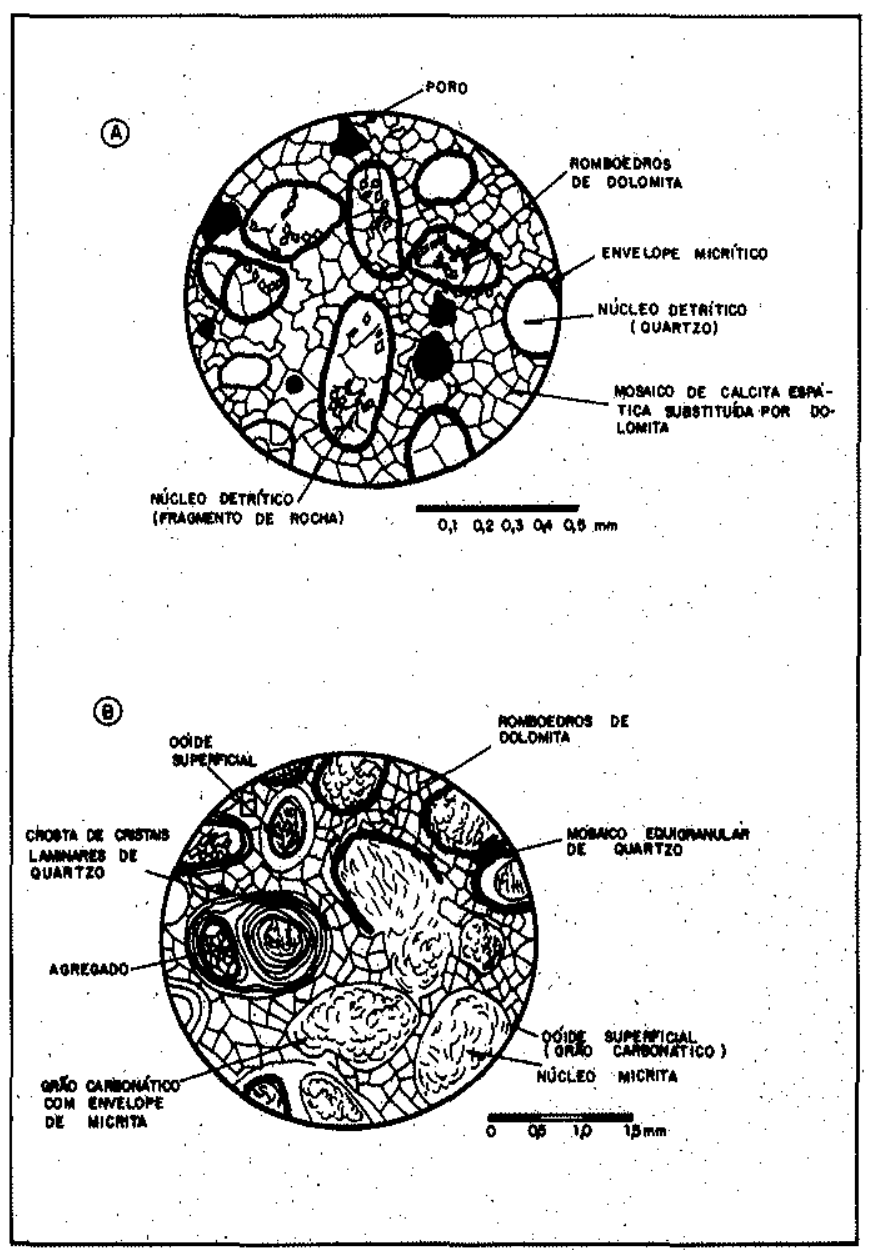

Figura 3 - Elementos da textura dos calcarenitos da fácies AC: A) calcarenito oolítico dolomitizado; $e$ B) calcarenito oolitico silicificado

A distribuição de oóides e agregados obsetvada nos oceanos modernos demonstra que esses tipos de grãos carbonáticos estấo restritos a águas rasas e quentes dominadas pela associação clorozoan de grãos esqueletais, a qual inclui corais hermatípicos e algas calcárias verdes (Sellwood 1980). Ademais, a maioria dos sítios atuais de ativa formação de oóides e agregados está concentrada perto dos trópicos, onde as taxas de precipitação sâo menotes que as taxas de evaporação enquanto as faixas oceânicas próximas ao equador, carentes de obides e agregados, tềm sua salinidade dilứda pela pesada precipitação. Nestas condições, as margens externas das plataformas continentais modernas sâo sítios preferenciais de desenvolvimento das faix as arenosas lineares paralelas à aresta da plataforma em profundidade de $3.5 \mathrm{~m}$. As regiónes das plataformas caracterizadas por curtos períodos de agitação no fundo seguidos por períodos mais longos de estabilidade permitem o desenvolvimento de agregados. $\mathrm{Na}$ plataforma das Bahamas, as condiçðes propícias à deposição de agregados (grapestones) encontram-se em áreas onde o nível de turbulência seja intermediário entre as lagunas dominantemente lamosas e os bancos de areias ooliticas.

0 crescimento dos obides está claramente relacionado à turbulência e da passagem de uma lâmina delgada de água 
hipersalina formando duas correntes de sentidos opostos sobre a margem rasa da plataforma. A correlação entre os agregados e um meio menos turbulento deriva da necessidade de os grâos jazerem em contato permanente por tempo suficientemente longo, de forma a permitir sua cimentação. Os calcarenitos bioclásticos associados podem representar níveis de concentração de fragmentos algais derivados da desintegração de construçōes orgânicas nestas áreas de alta energia.

Modelo Deposicional da Formação Acauã A formulação de um modelo deposicional para os carbonatos da Formação Acauã pressupõe que o arranjo vertical das fácies corresponde à migração lateral de ambientes de sedimentação contíguos, em resposta a flutuaçōes do nivel de base regional da bacia Estância. Tal abordagem é limitada pelo fato de o elevado grau de recristalização imprimido a estas rochas e a ausência de fósseis dificultarem a reconstituição segura e pormenorizada dos processos sedimentares envolvidos na deposição de grande parte do pacote. A figura 4 ilustra a distribuição geográfica hipotética das fâcies de um modelo estático, baseado nos sistemas de plataformas carbonáticas modernas como as Bahamas, Honduras Britânicas e o Golfo Pérsico (Bathurst 1976, Sellwood 1980) e nos modelos conceituais de faixas de fácies padrão de Wilson (1975).

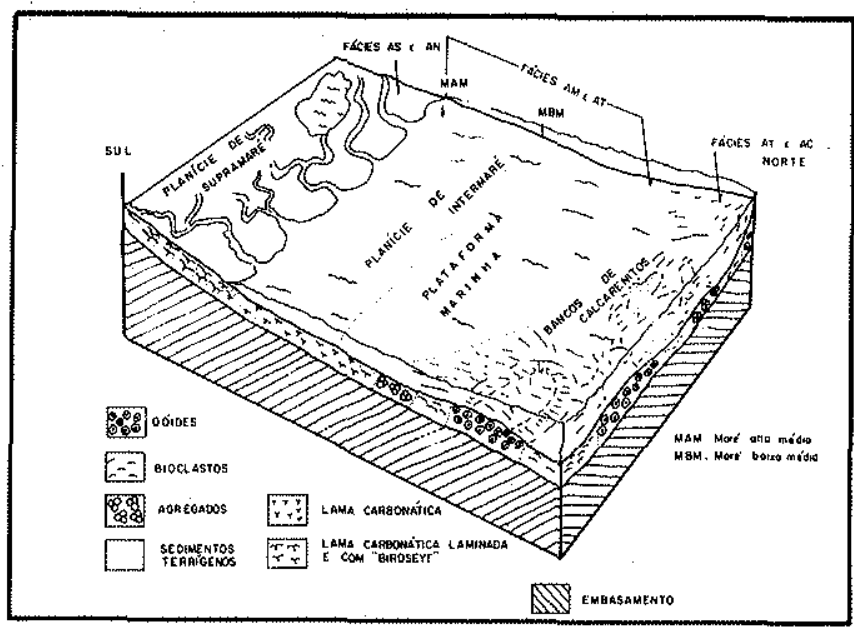

Figura 4 - Esquema representativo dos ambientes de deposição das diferentes fácies da Formação Acauã

Nas porções inferiores da formação, encontram-se lamas com laminaçðes possivelmente de origem algal e estruturas de escape de gases, além de evidências de águas com altas salinidades propiciando o crescimento de cristais e veios de gipso. A fácies AS seria assim o resultado de acumulação de lamas em amplas planícies de supramaré. A dolomitização dessas lamas requer valores elevados para a razão molar $\mathrm{Mg}^{+2} / \mathrm{Ca}^{+2}$ em salmouras com salinidades cinco a seis vezes maiores que a salinidade normal de água do mar. Essas salmouras podem precipitar gipsita retirando $\mathrm{Ca}^{+2}$ da água com o conseqüente aumento da razão $\mathrm{Mg}^{+2} / \mathrm{Ca}^{+2}$ e promovem uma supersaturação em dolomita. Sighinolfi et al. (1977) desenvolveram estudos geoquímicos em amostras de carbonatos da região de Crisópolis, que demonstraram a existência de uma marca do decréscimo da razão $\mathrm{Ca} / \mathrm{Mg}$ com o aumento do con teúdo em sflica nos dolomitos e sugerem uma conexão entre os processos de dolomitização e silicificação, através do abaixamento do $\mathrm{pH}$ do ambiente durante a dolomitização, saturação e precipitação de sílica. Admitem que a dissolução dos carbonatos primários (calcita magnesiana e aragonita) com saturação em dolamita e abaixamento do $\mathrm{pH}$ com precipitação de sílica é atingida pelo influxo de águas meteoricas em zonas de intermarés. As feiçðes exibidas pela silicificação na fácies de dolomitos sili: cosos, bem como, em menor grau no restante da seqüência, levam a admitir que o processo de dissolução se deu de maneira seletiva aproveitando planos estratificação ou a calcita espática cimentante dos calcarenitos.

$O$ avanço da linha de costa para sul faz com que esses dolomitos de supramaré sejam recobertos por lamas de inter e inframaré (fácies AM), em condiçoes de plataforma marinha restrita (fácies padrão 8 de Wilson 1975), responsável pelo caráter dolomítico dessas rochas, que são por sua vez, no clímax da transgressão marinha, recobertas pelas areias carbonáticas da margem da plataforma (fácies AC). A partir daI, inicia-se então um perfodo regressivo que marca a parte média a superior da formação com a progradação das lamas de plataforma restrita (fácies AM) e culminando com calcilutitos pretos (fácies AN), que mostram evidências de deposição em áreas isoladas na supramaré, como baías alimentadas por águas marinhas durante períodos de marés excepcionalmente altas.

CONCLUSÓES A Formação Acauã registra o advento de uma ampla transgressão marinha no âmbito do Sistema de Dobramentos Sergipano e atesta um período de grande estabilidade tectônica, com a instalação de um mar plataformal raso que passa a desenvolver importante sedimentação carbonática. Esta unidade assenta sobre os terrígenos da Formação Juetê em contato abrupto e está composta por uma assembléia de fácies sedimentares indicativas de deposição em planícies de supramaré, plataforma marinha rasa restrita e cinturões de areias oolíticas de margem de plataforma.

A base da unidade está constiturda por carbonatos de supramaré, recobertos na porção intermediária por depósitos transgressivos de plataforma restrita e por areias carbonáticas de acumulações de margem de plataforma. Constantes intercalaçōes de argilitos atestam interrupções da sedimentação carbonática por influxo periódico de terrígenos finos à bacia. As fácies com características típicas de supramaré dominam a parte superior da formação, com o aparecimento de sedimentos depositados sob condiçбes redutoras em áreas de águas estagnadas nas planícies de supramaré. 0 caráter dolomítico e silicoso é mais importante nas porções inferiores da sucessão $e$ as areias carbonáticas da parte intermediária mostram um registro bem documentado dos processos diagenéticos que ocorreram nesses carbonatos.

Agradecimentos Os autores deixam aqui expressos os agradecimentos ao Conselho Nacional de Desenvolvimento Científico e Tecnológico, pelo apoio financeiro recebido (Proc. CNPq n.0 40.0516/81) sem o qual não teria sido possível a realização do presente trabalho. Agradecimentos são extensivos ao Professor Abilio C.S.P. Bittencourt, pelas críticas e sugestðes apresentadas; ao Professor Umberto $\mathbf{R}$. Costa e a Buhomila Araújo, pela versão do resumo para o inglês; e a Gilzélio Nascimento e Natanael P. Gomes, pelos trabalhos de datilografia e desenhos, respectivamente. 


\section{REFERENCIAS BIBLIOGRAFICAS}

BATHURST, R.G.C. - 1976 - Carbonate sediments and their diagenesis. Developments in sedimentology 12. Amsterdam, Elsevier, $658 \mathrm{p}$.

BRITO NEVES, B.B.; KAWASHITA, K.; MELLO, E.Z.V. - 1977a Estudo Geocronológico do Grupo Estância pelo método do $\mathrm{Rb} / \mathrm{Sr}$. In: SIMP. GEOL. NORDESTE, 8 Campina Grande, 1977. Atas..., Campina Grande, SBG, p. 311-321.

BRITO NEVES, B.B.; SIAL, A.N.; ALBUQUERQUE, J.P.T - 1977bVergência centrífuga residual no Sistema de Dobramentos Sergipano, Rev. Bras. Geoc., 7(2);102-114.

CHOQUETTE, P.W. \& PRAY, L.C. * 1970 - Geological nomenclature and classification of porosity in sedimentary carbonates. Am. Assoc. Petrol. Geol. Bull., 54:207-250.

DUNHAM, R.J. - 1962 - Classification of carbonate rocks according to depositional texture. In;HAM, W.E. ed., Classification of carbonates rocks. Amer. Assoc. Petrol. Geol. p. 108-121 (Memoir 1).

FOLK, R.L. - 1962 - Spectral Subdivision of limestones types. In; HAM, W.E. ed., Classification of carbonates rocks. Amer. Assoc. Petrol. Geol. p. 52-84 (Memoir 1).

HUMPREY, F.L. \& ALLARD, G.O. - 1969 - Geologia da área do domo de Itabaiana e sua relação com a geossinclinal de Propriá. Rio de Janeiro, Petroobras-Cenpes, $160 \mathrm{p}$.

SAES, G.S. \& VILAS BOAS, G.S. - 1983 - Fácies sedimentares da Formação Lagarto, Pré-Cambtiano Superior no extremo nordeste da Bahia. Rev, Bras. Geoc., 13(4):263-270.

SAES, G.S. - 1984 - Estratigrafia e sedimentologia do Grupo Estância na Região Nordeste do Estado da Bahia. Salvador (Dissertação de Mestrado, UFBA), $104 \mathrm{p}$.

SAES, G.S. \& VILAS BOAS, G.S. - 1984 - Depósitos de "fan deltas" da Formação Palmares:Pré-Cambriano Superior no nordeste da Bahia. In:CONGR. BRAS. GEOL. 33. Rio de Janeiro, 1984. Bol. Resumos..., Rio de Janeiro, SBG, p. 55.
SELLWOOD, B.W. - 1980 - Shallow water carbonate environments. In:READING, H.G. ed., Sedimentary environments and facies. London, Blackweel Scientific pub. p. 259-313.

SHINN, E.A. - 1968 - Practical significance of birdseye structures in carbonate rocks, Jour Sed. Pet., 38(1):215-223.

SIGHINOLFI, G.P.; VILAS BOAS, G.S.; MATTOSO, S.Q.; GORGONI, C. - 1977 - Uppex precambrian dolomites from Crisópolis (Bahia):chemical and petrogenetic study. Rev. Bras. Geoc., 7(3):221-229.

SILVA FILHO, M.A.; BONFIM, L.F.C.; SANTOS, R.A.; SANTANA, A.C.;BRAZ FILHO, P.A. - 1977 - Geologia da Geossinclinal Sergipana e do seu Embasamento. Projeto Baixo São Francisco Vaza Barris. Brasilia, DNPM. 131 p.

SILVA FILHO, M.A.;SANTANA, M.O.;BONFIM, L.F.O. - 1978 Evoluçãa testono-sedimentar do Grupo Estância; suas correlaç̃es. In: CONGR. BRAS. GEOL., 30, Recife, 1978. Anais..., Recife, SBG, v. 2, p. 685-699.

WILSON, J.L. - 1975 - Carbonate facies in geologic history. New York, Springer-Verlag. $471 \mathrm{p}$.

"Os homens estudam um certo número de fatos... classificam, analisam, descobrem relações e sequiências e, então, descrevem da maneira mais simples o mais amplo alcance possível do fenômeno... Conseqüentemente, entendemos por lei em ciência o resumo mental que substitui a extensa descrição de sequêências feita por nossas impressões sensoriais... Tais leis simplesmente descrevem, nunca explicam ..."

Karl Pearson. 1900, págs. 86-87, 99. 